\title{
The Arts End of the World: Creating a Creative Nation?
}

\author{
Michael Harris
}

7 The Australian federal government's 'cultural statement', Creative Nation: Commonwealth Cultural Policy (1994), may well be the first document of

1 its kind anywhere. However, the rarity of explicit artistic manifestos does not mean that governments are inactive in the consumption and the production of the arts. There appears to be a sufficiently (which is not to say universally) recognised prima facie case for public financial support for arts bodies and individual artists, based on the assumption that the market is a flawed instrument for ensuring the creation of 'sufficient' or 'worthwhile' art and for rewarding artists 'appropriately'. Such support is evident in many (and not just industrialised) countries. (Of course, whether such patronage stems from a desire to rectify the market's flaws or, as in the case of sport, from other imperatives such as national prestige, is another question.)

Public responses to Creative Nation have been, at least on one level, predictable. Arts advocates and 'industry spokespeople' seem to approve of the document, whether because of its express intentions or because it shows that the Keating Government is interested in the arts and willing to back them with cash. But equally unsurprising has been the number of commentators expressing cynicism about government-sponsored arts industries.

How then does one evaluate Creative Nation? At an economic level, one might assess the degree to which its proposals address market failures: in other words, does the document deal with the prima facie case for arts support outlined above? Is it intended to increase the quantity or quality of works of art produced; to increase the public's consumption and appreciation of art; to improve the rewards to artists for work they would have produced anyway; to involve isolated and marginal communities in the creation and consumption of art; to maintain prestigious organisations whose inevitable 'labour intensiveness' results in ever-increasing production costs; to provide short-term subsidies to unknown but promising artists in order to help them become self-sufficient; or something else?

At a cultural level, one might examine the artistic assumptions underlying the document's proposals and their likely outcomes. That is to say, what sort of art might result from their implementation? Does the document aim to produce particular outcomes or to improve processes?

At a political level, Creative Nation could be interpreted as part of a broader political framework (another element of which might be the push for a republic) that reflects the vision of, in particular, the Prime Minister. (It seems widely ac- 
cepted that Mr Keating played a major role in framing the direction of the cultural statement and that he sees it as an element in his drive to 'reinvent' Australia.)

One way of linking these three levels of analysis is to recognise that arts policies can take 'bottom-up' or 'top-down' approaches. A bottom-up approach involves identifying particular problems and trying to devise sensible solutions, while leaving the actual doing of the art to the artists. Such methods would be addressed to the kind of policy goals, listed above, designed to deal with market failures. They could include augmentation of royalties; fixed-term scholarships for less well-known artists; or investment in particular items of infrastructure only if subject to some form of cost-benefit analysis. A good strategy of this kind would also be mindful of, and try to minimise, the ever-present dangers of politics and of powerful cliques distorting the purposes of the policy.

A top-down approach, in contrast, starts with a 'vision' of where (and perhaps what) the arts should be, rather as an activist industry policy produces a 'blueprint' of the sort of industrial structure a nation should have. The task is then one of creating the outcome, rather than the preconditions, of artistic endeavour. The height of the 'top' of top-down policies can vary. Such policies may be concerned with 'art for art's sake', a creative grand design aimed at achieving goals like 'excellence' and 'international recognition' in major fields of the arts. Or they may be, as Creative Nation arguably is, handed down from even loftier heights, as part of a design in which the nation's very 'identity' is at stake.

Creative Nation has the hallmarks of a grand design, even before the first page is turned. The fancy label 'cultural statement' rather than the more mundane 'arts policy' suggests big things to come. The document itself is glossy and shiny, reinforcing the notion that art and culture are defined and judged, at least in part, by high production values. By just browsing through the document, the reader can find plenty of indications that this is a statement concerned with big agendas, big institutions and big ideas. Summits are called for, major organisations are given triennial funding, centres of training excellence are proposed, and at least two Sydney institutions - the National Institute of Dramatic Art and the Sydney Symphony Orchestra - get what is arguably privileged status over their interstate counterparts.

Meanwhile, the major body for providing funds to individual artists, the Australia Council, appears to suffer not at all from the criticism it has been receiving recently from individual artists who regard it as clique ridden and politically driven. The shift to triennial funding for the Council may be defensible on other grounds, but those practitioners who feel the Council is in need of major reform will not be heartened by the statement's silence on the subject.

The statement includes a number of examples of government preparing to involve itself in areas where the immediate rationale for intervention is unclear: for example, its proposed high-tech, multi-media ventures into the information superhighway'. Since it is hard to get details about these matters from the document, we shall have to wait and see.

None of this is meant to suggest that Creative Nation contains nothing of merit. Some of its proposals are better than others (though it is notable that the issue of 
relaxing parallel importation restrictions on sound recording is dodged once again). But whereas lip service is paid to the notion of artistic endeavour as a spontaneous and fairly individualistic activity that evolves by means of its internal dynamics, the document endorses, and is firmly based on, the feel-good notion of Culture (with a capital C) as something that can be deliberately shaped so as to make us all feel good about ourselves.

Nowhere is this more evident than in the opening pages of the statement, particularly the preamble attributed to the Cultural Policy Advisory Panel, an elite of movers and shakers in the high art world. Apropos of nothing, the preamble opens with the line 'Democracy is the key to cultural value'. This is, to put it mildly, hard to interpret either in the context of Creative Nation or in any other context. Is Creative Nation meant to further the cause of art by advancing democracy? In what way is it a democratic document? Surely it is not suggested that quality art is produced only in democracies?

But this is not all that the Advisory Panel claims. Over the page is a succinct discussion of the significance of culture for a society. Here it is claimed that 'culture is the expression of a society's aesthetic, moral and spiritual values, indeed of its understanding of the world and of life itself ... [and it] is a measure of civilisation, at its best, enhancing and ennobling human existence'. This is the feel-good view of Culture run rampant. At its best, or otherwise, art can be exciting, dull, vulgar, escapist, challenging, confusing, rebellious, conformist, confronting, scandalous, elitist, subversive, funny, depressing, or obscure. The best artistic creations make some of us feel uncomfortable; this may not be incompatible with any 'enhancing and ennobling' effect, but it is not at all clear whether this is always so.

The real purpose of the Advisory Panel's lofty sentiments is to form a beautiful rhetorical backdrop for turning arts policy into a component of a grander social blueprint. The unspoken and unexamined assumption of Creative Nation is that, if culture makes us a better nation, then it must be a legitimate role of the state to foster and nurture the appropriate sorts of culture. Any artist of independent mind ought to be concerned at this. A truly creative nation cannot be created. It can be encouraged or stifled; and history seems to indicate that government interventions to do either of these can have the opposite effect.

Michael Harris is Lecturer in Agricultural Economics at the University of Melbourne. He wishes to point out that some of those closest to him are practising artists who have received government support. 